\title{
Biodiversity of Van Reeds, Eastern Turkey
}

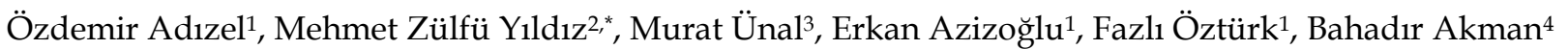

\author{
${ }^{1}$ Department of Biology, Faculty of Science, Van Yüzüncü Yıl Univesity, Van, Turkey \\ ${ }^{2}$ Department of Biology, Faculty of Science, Adyaman University, Adyaman, Turkey \\ ${ }^{3}$ Department of Mathematics and Science Education, Faculty of Education, Van Yüzüncü Yıl University, Van, Turkey \\ ${ }^{4}$ Çınar Engineering Consulting Co., Ankara, Turkey
}

\begin{abstract}
Received: 29.11.2017
Accepted: 22.12 .2017

Available online: 25.12 .2017

Published: 29.12 .2017

Abstract: In this study, it is aimed to determine the vertebrate fauna and flora species diversity of Van Reeds. For this purpose, studies were conducted between 2014 and 2017 and 1 fish, 3 frog, 6 reptilian, 185 bird, and 5 mammal species, 200 fauna species and 79 flora species in total, were determined in the study area. Van Reeds is an important breeding, feeding, and wintering feature especially for birds. Reeds, which has various biodiversity, is exposed to intense pressure and destruction. The main threats in the study area are construction, filling, hunting, drainage, and pollution.

Keywords: Pearl mullet, amphibia, reptilia, bird, biodiversity

\section{Van Sazlı̆̆ı'nın Biyoçeşitliliği}

Özet: Bu çalışma ile, Van ilinin Edremit ilçesi sınırları içerisinde yer alan Van Sazlığı́nın omurgalı fauna ve flora tür çeşitliliğinin belirlenmesi amaçlanmıştır. Bu amaçla, 2014-2017 yılları arasında yapılan çalışmalar sonucunda alanda 1 balık, 3 kurbağa, 6 sürüngen, 185 kuş ve 5 memeli olmak üzere 200 fauna elemanı ve 79 flora elemanı tespit edilmiştir. Van Sazlığı özellikle kuşlar için önemli bir üreme, beslenme ve kışlama özelliğini taşımaktadır. Biyoçeşitliliği yüksek olan sazlık, yoğun baskı ve tahribatlara maruz kalmaktadır. Alandaki başlıca tehtidler; yapılaşma, dolgu, av, drenaj ve kirlenme olarak belirlenmiştir.
\end{abstract}

Anahtar kelimeler: Van balığı, kurbağa, sürüngen, kuş, biyoçeşitlilik

\section{Giriş}

Biyolojik çeşitlilik; kara, deniz ve diğer su ekosistemleri ile bu ekosistemlerin bir parçası olan ekolojik yapılar da dahil olmak üzere tüm kaynaklardaki tür çeşitliliği, genetik çeşitlilik ve ekosistem çeşitliliğinin tamamının bir bütünüdür (Kaşlığlu ve Berkes 1987). Ekosistemlerin sahip olduğu bütünlük ve çeşitlilik, iklim, yağış rejimi, tür sosyolojisi gibi doğal dengelerin devamında önemli işlevler görür. Ülkemiz, biyolojik çeşitlilik açısından oldukça zengindir (Kence 1987). Öncelikle sahip olduğumuz bu zenginliğin envanterinin alan bazlı çıkarılması ve izlenmesi gerekir.

Van Sazlığı, Van ilinin Edremit İlçesi ile Van İskelesi arasında kalan önemli bir sulak ekosistemidir. Çalışma alanı ile ilgili kaynaklarda görüleceği gibi sahanın isimlendirilmesi ile ilgili karışıklık mevcuttur. Bazı kaynaklarda Van Sazlığı ve Edremit Sazlığı olarak iki ayrı alan olarak verilmektedir (Schilperoord ve SchilperoordHuisman 1986, Kasparek 1989, Anonim 1993, Van den Berk ve ark. 1993, Kılıç ve Eken 2004). Diğer bazı kaynaklarda ise tek saha olarak kabul edilmiştir. Bazı literatürlerde ise Van Gölü'nün doğu kıyıları olarak geçmektedir (Van der Ven ve Gheyselinck 1980).

Van havzası ve Van Sazlığg'nın kuş biyoçeşitliliği ve bazı biyolojik ve ekolojik özellikleri hakkında bazı çalışmalar mevcuttur (Vielliard 1968, Kumerlove 1969, Van der Ven ve Gheyselinck 1980, Schilperoord ve Schilperoord-Huisman 1986, Kasparek 1989, Yarar ve Magnin 1997, Adızel 1998, Kılıç ve Eken 2004). Diğer fauna ve flora türleri ile ilgili ise çok sınırlı sayıda çalışma yapılmıştır (Zeyrek ve Öztürk 1993, Behçet ve Altan 1994, Mulder 1995, Baran and Atatür 1998).

$\mathrm{Bu}$ çalışma ile Van Sazlığı'nın biyolojik çeşitliliğinin belirlenmesi ve yapilacak olan koruma ve izleme çalışmalarına temel oluşturulması amaçlanmıştır.

\section{Materyal ve Metod}

Çalışma alanı, Edremit İlçesi ile Van İskelesi arasında kalan Van Gölü'nün doğu kıyısıdır. Sahanın iki ucu $38 \mathrm{~S}$ $353050 \mathrm{D}-4264640 \mathrm{~K}$ ve 38 S 353593 D-4258655 K koordinatları arasında kalmaktadır (Şekil 1). Alan ince bir kum bandı ile gölün sodalı suyundan ayrılmaktadır. Geçmişteki doğal eşikleri çok geniş olsa da; günümüzdeki sazlık kıyı çizgisi boyunca yer yer dar kesik, sığ lagünlerden ibarettir. Van Kalesi kesiminde lagün ve sazlıklar genişleyerek karaya doğru ilerlemiştir (Şekil 2). Buna mukabil sulak alan diğer bazı kesimlerde de tamamen kesintiye uğramış durumdadır. Dar sazlık bandından sonra islak çayırlar bulunur. Devamında tarlalar ve sonrasında seyrek ağaçlık kesim vardır. Lagünleri besleyen en önemli su kaynakları Akköprü Deresi ve Şamran Suyu'dur. Bunun dişında Yağışlar ve küçük su akışları lagünleri desteklemektedir. Van Kalesi ve havaalanı sazlığın geçmiş doğal sınırları içinde yer almaktadır. Havaalanının güney ucu halen mevcut sazlık içindedir.

Bu çalışma Temmuz 2014-Haziran 2017 arasında yürütülmüştür. Uzmanlar, çalıştıkları grupların aktivasyon, üreme, göç, çiçeklenme ve vejetasyon dönemlerini göz önünde tutarak en uygun aylarda arazi çalışmaları gerçekleştirmişlerdir. Alanın ornitolojik 
açıdan çok önemli olmasından dolayı her ay en az bir gün alanda kuş gözlemi yapılmıştır. Özellikle kuşların göç mevsiminde arazi çalışmaları yoğunlaştırılmıştır. Genel olarak 06:00 ile 18:00 saatleri arasında arazi çalışmaları gerçekleştirilmiştir. Hava koşullarının uygun olduğu günlerde nokturnal türleri tespit etmek amaciyla çalışmalar 24:00'a kadar devam etmiştir. Ornitolojik gözlemlerde dürbün, teleskop ve SLR fotoğraf makinesi, bataklık giysileri, teşhis kitapları kullanılmıştır. Kuşlar için genelde hakim noktadan ve hat boyu gözlemler yapılmıştır. Bu amaçla Dobinson (1976) kuş sayım yönteminden faydalanılmıştır.

Herpetolojik çalışmalar için örnekler elle veya kepçe ile yakalanarak teşhis edilmiştir. Arazi çalışması sonunda örneklere ait renk ve desen özellikleri not edilmiş, gözlenen sürüngenlerin ve habitatlarının fotoğraflarının çekilmesinde dijital fotoğraf makinesi (Nikon D300s) kullanılmıştır. Fotoğrafı çekilen örnekler ekolojik dengeye zarar vermemek adına doğasına salıverilmiştir. Türlerin belirlenmesinde teşhis anahtarlarından ve güncel literatürden faydalanılmıştır (Baran ve Atatür, 1998). Üreme dönemlerinde en uygun günlerde arazi çalışması yapılarak kurbağa ve sürüngen türlerinin belirlenmesi sağlanmıştır. Ayrıca nokturnal türler için gece arazi çalışmaları da düzenlenmiştir.

Alandaki bitkilerin tespiti amaciyla araziden herbaryum tekniklerine uygun olarak örnekler toplanmıştır. Arazi çalışmasında toplanan flora materyalleri Davis 1965-1985, Davis ark. 1988 ve Güner ve ark. 2000 eserlerinden faydalanılarak teşhis edilmiştir.

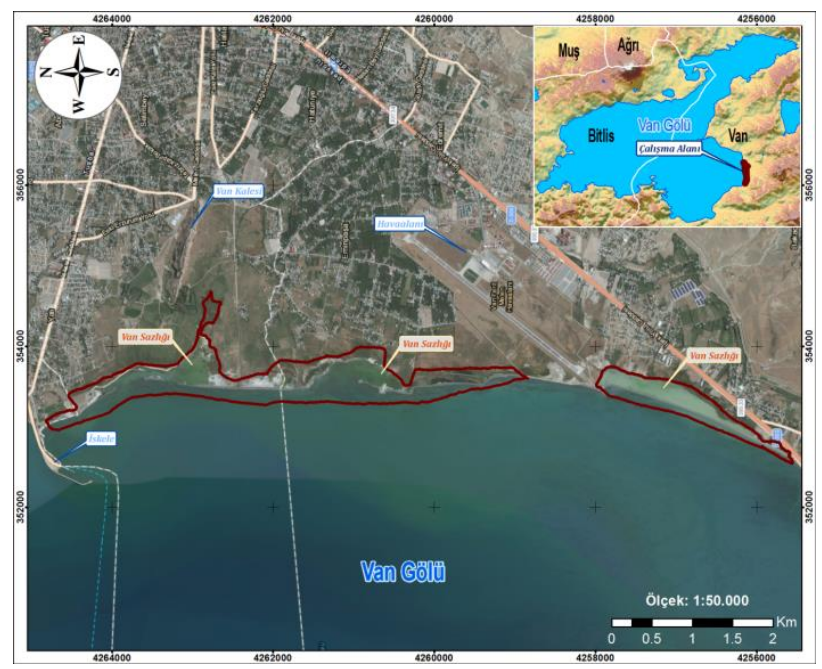

Şekil 1: Alanın konumu ve uydu görünümü

\section{Sonuçlar}

\subsection{Ornitolojik sonuçlar}

Gözlemler sonucu alan sınırları içinde ve yakın çevresinde yaşayan 16 takımdan 46 familya içinde yer alan 185 kuş türü tespit edilmiştir (Tablo 1). Bu türlerin 56'sı Yerli (Y), 82'si Göçmen (G) veya Yaz Ziyaretçisi, 28'i Kış Ziyaretçisi (KZ) ve 19'u ise Transit (T) veya Transit Göçer olarak belirlenmiştir.

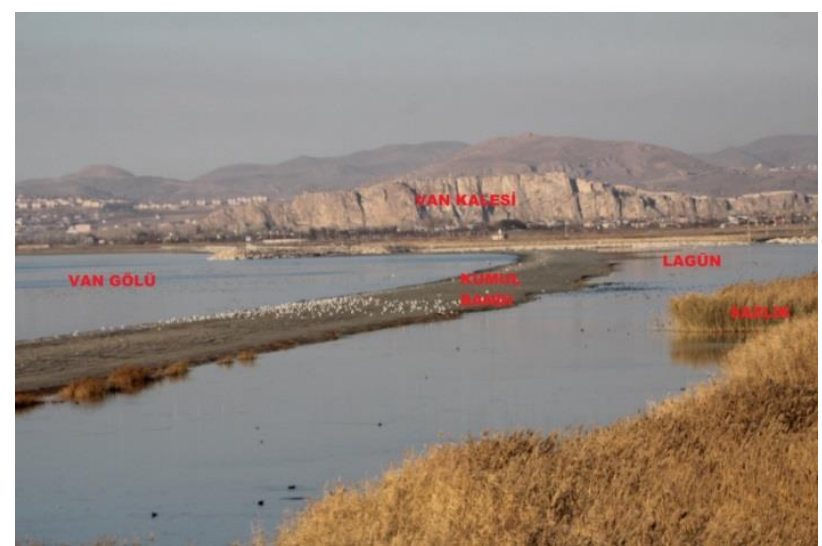

Şekil 2: Alanın genel görünümü

Alanda tespit edilen türlerden Dikkuyruk (Oxyura leucocephala), IUCN kriterlerine göre tehlike altındadır (EN=Endangered) (Şekil 3). Bu statüde bulunan türlerin doğada soyu tükenme tehlikesi ihtimali çok yüksektir. Bunun dişında 4 kuş türü (Bozkır Delicesi, Çamur Çulluğu, Kervan Çulluğu ve Gök Kuzgun) NT (Near Threatened) statüsündedir. Bu statüdeki türler şu anda tehlikede olmayan fakat yakin gelecekte VU, EN ve CR tehlike kategorilerine girmeye aday olan türlerdir. Geriye kalan 180 tür LC (Last Concern) statüsünde sinıflandırılmaktadır. Ayrıca 62 tür Van Sazlığı'nda üreyen, 76 tür ise büyük ihtimal ile yakın çevrede üremeyen türlerdir. 132 tür Bern Sözleşmesi'ne göre sıkı koruma altında ve 45 tür koruma altında yer alırken geriye kalan 8 tür Bern Sözleşmesi ek listelerinde yer almamaktadır. 21 kuş türü CITES Sözleşmesi ile uluslararası ticareti yasaklanan türler listesinde yer almaktadır. Ayrıca listede yer alan 50 kuş türü, Merkez Av Komisyon kararı ile koruma altında olan türlerden oluşmaktadır (Tablo 1).

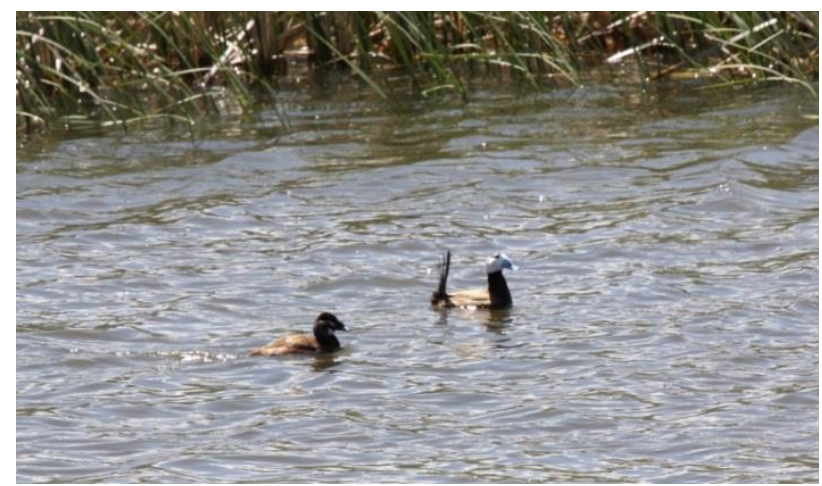

Şekil 3: Alanda üreyen Dikkuyruk (Oxyura leucocephala)

\subsection{Alanda Yaşayan Diğer Fauna Taksonları}

Van Sazlığı'nda belirlenen tek balık türü Van Balığ1 (Alburnus tarichi)'dır. Üreme mevsiminde tatlisu kaynaklarında da gözlenen Van Balığı, üreme sezonu dışında alanın göl kesiminde, sodalı suda bulunmaktadır. Çalışma alanında 3 familyaya ait 3 farklı kurbağa türü tespit edilmiştir (Tablo 2). Bataklık kurabağası (Pelophylax ridibundus) sadece lagüne dökülen tatlısu kaynaklarında, Değişken desenli gece kurbağası (Bufotes variabilis) ve Toprak kurbağası (Pelobates syriacus) türleri ise karasal 
Tablo 1: Van Sazlığı' nda gözlenen kuş türleri

\begin{tabular}{|c|c|c|c|c|c|c|c|c|c|}
\hline Bilimsel Adı & Türkçe Adı & İngilizce Adı & IUCN & CITES & BERN & MAKK & $\begin{array}{l}\text { Bölge } \\
\text { Statü }\end{array}$ & RDB & Üreme \\
\hline \multicolumn{10}{|l|}{ Podicipediformes } \\
\hline \multicolumn{10}{|l|}{ Podicipedidae } \\
\hline Tachybaptus ruficollis & Küçük Batağan & Little Grebe & LC & - & II & - & $\mathrm{Y}$ & A.3.1 & + \\
\hline Podiceps cristatus & Tepeli Batağan - Bahri & Great Crested Grebe & LC & - & III & - & Y & A. 5 & + \\
\hline Podiceps grisegena & Kızıl Boyunlu Batağan & Red-necked Grebe & LC & - & II & - & G & A. 3 & - \\
\hline Podiceps nigricollis & Karaboyunlu Batağan & Black-necked Grebe & LC & - & II & - & Y & A. 4 & + \\
\hline \multicolumn{10}{|l|}{ Ciconiiformes } \\
\hline \multicolumn{10}{|l|}{ Ardeidae } \\
\hline Botaurus stellaris & Balaban & Eurasian Bittern & LC & - & II & - & G & A. 2 & - \\
\hline Ixobrychus minutus & Küçük Balaban & Little Bittern & LC & - & II & - & G & A. 2 & - \\
\hline Nycticorax nycticorax & Gece Balıkçılı & $\begin{array}{l}\text { Black-crowned Night } \\
\text { Heron }\end{array}$ & LC & - & II & - & G & A.3.1 & - \\
\hline Ardeola ralloides & Alaca Balıkçıl & Squacco Heron & LC & - & II & - & $\mathrm{T}$ & A. 3 & - \\
\hline Bubulcus ibis & Öküz Balıkçılı & Western Cattle Egret & LC & - & II & - & G & A. 2 & - \\
\hline Egretta garzetta & Küçük Akbalıkçıl & Little Egret & LC & - & II & - & G & A.3.1 & - \\
\hline Ardea alba & Büyük Akbalıkçıl & Great Egret & LC & - & II & - & G & A.3 & - \\
\hline Ardea cinerea & Gri Balıkçıl & Grey Heron & LC & - & III & I & Y & A.3.1 & - \\
\hline Ardea purpurea & Erguvani Balıkçıl & Purple Heron & $\mathrm{LC}$ & - & II & - & G & A. 2 & - \\
\hline \multicolumn{10}{|l|}{ Ciconiidae } \\
\hline Ciconia ciconia & Ak Leylek & White Stork & $\mathrm{LC}$ & - & II & - & G & A.3.1 & + \\
\hline \multicolumn{10}{|l|}{ Threskiornithidae } \\
\hline Plegadis falcinellus & Çeltikçi & Glossy Ibis & $\mathrm{LC}$ & - & II & - & $\mathrm{T}$ & A.3.1 & - \\
\hline \multicolumn{10}{|l|}{ Phoenicopteriformes } \\
\hline \multicolumn{10}{|l|}{ Phoenicopteridae } \\
\hline Phoenicopterus roseus & Flamingo & Greater Flamingo & LC & II & II & - & $\mathrm{T}$ & A.3.1 & - \\
\hline \multicolumn{10}{|l|}{ Anseriformes } \\
\hline \multicolumn{10}{|l|}{ Anatidae } \\
\hline Cygnus cygnus & Ötücü Kuğu & Whooper Swan & LC & - & II & - & $\mathrm{KZ}$ & A. 3 & - \\
\hline Anser albifrons & Sakarca & $\begin{array}{l}\text { Greater White-fronted } \\
\text { Goose }\end{array}$ & LC & - & III & II & $\mathrm{KZ}$ & B.5 & - \\
\hline Anser anser & Boz Kaz & Greylag Goose & LC & - & III & I & KZ & A. 4 & - \\
\hline Tadorna ferruginea & Angit & Ruddy Shelduck & LC & - & II & - & Y & A. 4 & - \\
\hline Tadorna tadorna & Suna & Common Shelduck & LC & - & II & - & Y & A.3.1 & - \\
\hline Mareca penelope & Fiyu & Eurasian Wigeon & LC & - & III & II & $\mathrm{KZ}$ & A. 5 & - \\
\hline Mareca strepera & Boz Ördek & Gadwall & LC & - & III & II & $\mathrm{Y}$ & A. 4 & - \\
\hline Anas crecca & Çamurcun & Eurasian Teal & LC & - & III & II & $\mathrm{KZ}$ & A. 5 & - \\
\hline Anas platyrhynchos & Yeşilbaş & Mallard & LC & - & III & II & Y & A. 5 & + \\
\hline Anas acuta & Kilkuyruk & Northern Pintail & LC & - & III & II & $\mathrm{KZ}$ & A. 5 & - \\
\hline Spatula querquedula & Çıkrıkçın & Garganey & LC & - & III & II & G & A. 4 & - \\
\hline Spatula clypeata & Kaşıkgaga & Northern Shoveler & LC & - & III & I & $\mathrm{KZ}$ & A. 4 & - \\
\hline Netta rufina & Macar Ördeği & Red-crested Pochard & LC & - & III & II & G & A. 5 & + \\
\hline Aythya ferina & Elmabaş Pakta & Common Pochard & VU & - & III & II & Y & A. 5 & + \\
\hline Aythya fuligula & Tepeli Patka & Tufted Duck & $\mathrm{LC}$ & - & III & II & $\mathrm{KZ}$ & A. 5 & - \\
\hline Oxyura leucocephala & Dikkuyruk & White-headed Duck & $\mathrm{EN}$ & II & II & - & G & A. 2 & - \\
\hline \multicolumn{10}{|l|}{ Falconiformes } \\
\hline \multicolumn{10}{|l|}{ Accipitridae } \\
\hline Milvus migrans & Kara Çaylak & Black Kite & LC & II & II & - & G & A. 3 & - \\
\hline Circaetus gallicus & Yılan Kartalı & Short-toed Snake Eagle & LC & II & II & - & G & A. 4 & - \\
\hline Circus aeruginosus & Saz Delicesi & Western Marsh Harrier & LC & II & II & - & G & A. 3 & - \\
\hline Circus cyaneus & Gökçe Delice & Hen Harrier & $\mathrm{LC}$ & II & II & - & $\mathrm{KZ}$ & A.1.2 & - \\
\hline Circus macrourus & Bozkır Delicesi & Pallid Harrier & NT & II & II & - & $\mathrm{T}$ & A.1.2 & - \\
\hline Circus pygargus & Çayır Delicesi & Montagu`s Harrier & LC & II & II & - & G & A.1.2 & - \\
\hline Accipiter nisus & Atmaca & Eurasian Sparrowhawk & LC & II & II & - & $\mathrm{Y}$ & A. 3 & - \\
\hline Buteo buteo & Şahin & Common Buzzard & LC & II & II & - & $\mathrm{Y}$ & A. 3 & - \\
\hline Buteo rufinus & Kızıl Şahin & Long-legged Buzzard & LC & II & II & - & $\mathrm{Y}$ & A. 3 & - \\
\hline Aquila chrysaetos & Kaya Kartalı & Golden Eagle & LC & II & II & - & $\mathrm{Y}$ & A.1.2 & - \\
\hline Pandion haliaetus & Balık Kartalı & Western Osprey & $\mathrm{LC}$ & II & II & - & $\mathrm{T}$ & A.1.2 & - \\
\hline \multicolumn{10}{|l|}{ Falconidae } \\
\hline Falco naumanni & Küçük Kerkenez & Lesser Kestrel & LC & II & II & - & Y & A. 2 & - \\
\hline
\end{tabular}


Tablo 1 (devam)

\begin{tabular}{|c|c|c|c|c|c|c|c|c|c|}
\hline Bilimsel Adı & Türkçe Adı & İngilizce Adı & IUCN & CITES & BERN & МАKК & $\begin{array}{l}\text { Bölge } \\
\text { Statü }\end{array}$ & RDB & Üreme \\
\hline Falco tinnunculus & Kerkenez & Common Kestrel & $\mathrm{LC}$ & II & II & - & $\mathrm{Y}$ & A. 2 & + \\
\hline Falco subbuteo & Delice Doğan & Eurasian Hobby & $\mathrm{LC}$ & II & II & - & G & A.3.1 & - \\
\hline \multicolumn{10}{|l|}{ Galliformes } \\
\hline \multicolumn{10}{|l|}{ Phasianidae } \\
\hline Coturnix coturnix & Bildircin & Common Quail & $\mathrm{LC}$ & - & III & II & G & A.3 & - \\
\hline \multicolumn{10}{|l|}{ Gruiformes } \\
\hline \multicolumn{10}{|l|}{ Rallidae } \\
\hline Crex crex & Bıldırcın Kılavuzu & Corn Crake & $\mathrm{LC}$ & - & II & - & $\mathrm{KZ}$ & A.1.2 & - \\
\hline Porzana porzana & Benekli Sutavuğu & Spotted Crake & $\mathrm{LC}$ & - & II & - & $\mathrm{KZ}$ & A. 2 & - \\
\hline Zapornia parva & Bataklık Sutavuğu & Little Crake & $\mathrm{LC}$ & - & II & - & $\mathrm{KZ}$ & A.1.2 & - \\
\hline Zapornia pusilla & Küçük Sutavuğu & Baillon`s Crake & $\mathrm{LC}$ & - & II & - & $\mathrm{KZ}$ & A.1.2 & - \\
\hline Rallus aquaticus & Su Kılavuzu & Water Rail & $\mathrm{LC}$ & - & III & I & Y & A. 3 & - \\
\hline Gallinula chloropus & Saz Tavuğu & Common Moorhen & $\mathrm{LC}$ & - & III & I & Y & A.3.1 & + \\
\hline Porphyrio porphyrio & Saz Horozu & Purple Swamphen & $\mathrm{LC}$ & - & II & - & Y & A.1.2 & + \\
\hline Fulica atra & Sakarmeke & Eurasian Coot & $\mathrm{LC}$ & - & III & II & Y & A.5 & + \\
\hline \multicolumn{10}{|l|}{ Gruidae } \\
\hline Grus grus & Turna & Common Crane & $\mathrm{LC}$ & II & II & - & $\mathrm{T}$ & A.3 & - \\
\hline Grus virgo & Telli Turna & Demoiselle Crane & $\mathrm{LC}$ & II & II & - & $\mathrm{T}$ & A. 2 & - \\
\hline \multicolumn{10}{|l|}{ Charadriiformes } \\
\hline \multicolumn{10}{|l|}{ Haematopodidae } \\
\hline Haematopus ostralegus & Poyraz Kuşu & Eurasian Oystercatcher & NT & - & III & I & G & A.3 & - \\
\hline \multicolumn{10}{|l|}{ Recurvirostridae } \\
\hline Himantopus himantopus & Uzun Bacak & Black-winged Stilt & $\mathrm{LC}$ & - & II & - & G & A. 3 & + \\
\hline Recurvirostra avosetta & Kılıçgaga & Pied Avocet & $\mathrm{LC}$ & - & II & - & G & A. 4 & + \\
\hline \multicolumn{10}{|l|}{ Burhinidae } \\
\hline Burhinus oedicnemus & Kocagöz & Eurasian Stone-curlew & $\mathrm{LC}$ & - & II & - & G & A. 2 & - \\
\hline \multicolumn{10}{|l|}{ Charadriidae } \\
\hline Charadrius dubius & Küçük Halkalı Cılıbıt & Little Ringed Plover & $\mathrm{LC}$ & - & II & - & G & A. 3 & + \\
\hline Charadrius alexandrinus & Akça Cılıbıt & Kentish Plover & $\mathrm{LC}$ & - & II & - & G & A. 4 & + \\
\hline Vanellus spinosus & Mahmuzlu Kız Kuşu & Spur-winged Lapwing & $\mathrm{LC}$ & - & II & - & G & A.3 & - \\
\hline Vanellus vanellus & Kız Kuşu & Northern Lapwing & NT & - & III & $\mathrm{I}$ & G & A.5 & + \\
\hline \multicolumn{10}{|l|}{ Scolopacidae } \\
\hline Calidris minuta & Küçük Kumkuşu & Little Stint & $\mathrm{LC}$ & - & II & - & $\mathrm{KZ}$ & B. 5 & - \\
\hline Calidris temminckii & Sarıbacaklı Kumkuşu & Temminck`s Stint & $\mathrm{LC}$ & - & II & - & $\mathrm{KZ}$ & B. 3 & - \\
\hline Calidris alpina & Karakarınlı Kumkuşu & Dunlin & $\mathrm{LC}$ & - & II & - & $\mathrm{KZ}$ & B. 5 & - \\
\hline Limicola falcinellus & Sürmeli Kumkuşu & Broad-billed sandpiper & $\mathrm{LC}$ & - & II & - & $\mathrm{KZ}$ & B. 3 & - \\
\hline Calidris pugnax & Döğüşken Kuş & Ruff & $\mathrm{LC}$ & - & III & I & $\mathrm{T}$ & B. 4 & - \\
\hline Gallinago gallinago & Su Çulluğu (Bekasin) & Common Snipe & $\mathrm{LC}$ & - & III & II & $\mathrm{KZ}$ & В.3.1 & - \\
\hline Limosa limosa & Çamurçulluğu & Black-tailed Godwit & NT & - & III & I & $\mathrm{KZ}$ & B. 4 & - \\
\hline Numenius arquata & Kervançulluğu & Eurasian Curlew & NT & - & III & I & $\mathrm{KZ}$ & B. 3 & - \\
\hline Tringa totanus & Kizılbacak & Common Redshank & $\mathrm{LC}$ & - & III & I & G & A. 4 & + \\
\hline Tringa ochropus & Yeşil Düdükçün & Green Sandpiper & $\mathrm{LC}$ & - & II & - & $\mathrm{T}$ & B. 2 & - \\
\hline Actitis hypoleucos & Dere Düdükçünü & Common Sandpiper & $\mathrm{LC}$ & - & II & - & G & A.3 & + \\
\hline \multicolumn{10}{|l|}{ Phalaropodinae } \\
\hline Phalaropus lobatus & Deniz Düdükçünü & Red-necked Phalarope & $\mathrm{LC}$ & - & III & - & $\mathrm{T}$ & B.3.1 & - \\
\hline \multicolumn{10}{|l|}{ Laridae } \\
\hline Hydrocoloeus minutus & Küçük Martı & Little Gull & $\mathrm{LC}$ & - & II & - & $\mathrm{KZ}$ & B. 3 & - \\
\hline Larus ridibundus & Karabaş Martı & Black-headed Gull & $\mathrm{LC}$ & - & III & I & G & A. 5 & - \\
\hline Larus genei & İncegagalı Martı & Slender-billed Gull & $\mathrm{LC}$ & - & II & - & G & B. 4 & - \\
\hline Larus armenicus & Van Gölü Martısı & Armenian Gull & NT & - & III & I & Y & A. 3 & - \\
\hline Sternula albifrons & Küçük Sumru & Little Tern & $\mathrm{LC}$ & - & II & - & G & A.3.1 & - \\
\hline Sterna hirundo & Sumru & Common Tern & $\mathrm{LC}$ & - & II & - & G & A. 3 & - \\
\hline Chlidonias hybrida & Bıyıklı Sumru & Whiskered Tern & $\mathrm{LC}$ & - & II & - & $\mathrm{T}$ & A. 4 & - \\
\hline Chlidonias leucopterus & Akkanatlı Sumru & White-winged Tern & $\mathrm{LC}$ & - & II & - & G & A. 4 & - \\
\hline \multicolumn{10}{|l|}{ Columbiformes } \\
\hline Columbidae & & & & & & & & & \\
\hline Columba livia & Kaya Güvercini & Rock Dove & $\mathrm{LC}$ & - & III & II & Y & A. 5 & + \\
\hline Columba palumbus & Tahtalı Güvercin & Common Wood Pigeon & $\mathrm{LC}$ & - & - & II & G & A. 4 & - \\
\hline Streptopelia decaocto & Kumru & Eurasian Collared Dove & $\mathrm{LC}$ & - & III & $\mathrm{I}$ & G & A. 5 & - \\
\hline Streptopelia turtur & Üveyik & European Turtle Dove & $\mathrm{LC}$ & - & III & II & G & A.3.1 & - \\
\hline
\end{tabular}


Tablo 1 (devam)

\begin{tabular}{|c|c|c|c|c|c|c|c|c|c|}
\hline Bilimsel Adı & Türkçe Adı & İngilizce Adı & IUCN & CITES & BERN & МАКK & $\begin{array}{l}\text { Bölge } \\
\text { Statü }\end{array}$ & RDB & Üreme \\
\hline Spilopelia senegalensis & Küçük Kumru & Laughing Dove & $\mathrm{LC}$ & - & III & I & G & A. 4 & - \\
\hline \multicolumn{10}{|l|}{ Cuculiformes } \\
\hline \multicolumn{10}{|l|}{ Cuculidae } \\
\hline Cuculus canorus & Guguk Kuşu & Common Cuckoo & LC & - & III & - & G & A. 2 & - \\
\hline \multicolumn{10}{|l|}{ Strigiformes } \\
\hline \multicolumn{10}{|l|}{ Strigidae } \\
\hline Bubo bubo & Puhu & Eurasian Eagle-Owl & LC & II & II & - & $\mathrm{Y}$ & A.1.2 & - \\
\hline Athene noctua & Kukumav & Little Owl & $\mathrm{LC}$ & II & II & - & $\mathrm{Y}$ & A. 2 & + \\
\hline Asio otus & Kulaklı Orman Baykuşu & Long-eared Owl & LC & II & II & - & $\mathrm{Y}$ & A. 2 & + \\
\hline \multicolumn{10}{|l|}{ Caprimulgiformes } \\
\hline \multicolumn{10}{|l|}{ Caprimulgidae } \\
\hline Caprimulgus europaeus & Çobanaldatan & European Nightjar & LC & - & II & - & G & A.1.2 & - \\
\hline \multicolumn{10}{|l|}{ Apodiformes } \\
\hline \multicolumn{10}{|l|}{ Apodidae } \\
\hline Apus apus & Ebabil & Common Swift & $\mathrm{LC}$ & - & III & - & G & A.3.1 & + \\
\hline Tachymarptis melba & Akkarınlı Ebabil & Alpine Swift & LC & - & II & - & G & A.3.1 & + \\
\hline \multicolumn{10}{|l|}{ Coraciiformes } \\
\hline \multicolumn{10}{|l|}{ Alcedinidae } \\
\hline Alcedo atthis & Yalıçapkını & Common Kingfisher & LC & - & II & - & Y & A. 2 & - \\
\hline \multicolumn{10}{|l|}{ Meropidae } \\
\hline Merops apiaster & Arıkuşu & European Bee-eater & LC & - & II & - & G & A.3.1 & + \\
\hline \multicolumn{10}{|l|}{ Coraciidae } \\
\hline Coracias garrulus & Gök Kuzgun & European Roller & NT & - & II & - & G & A. 2 & + \\
\hline \multicolumn{10}{|l|}{ Upupidae } \\
\hline Upupa epops & İbibik & Eurasian Hoopoe & LC & - & II & - & G & A. 2 & + \\
\hline \multicolumn{10}{|l|}{ Piciformes } \\
\hline \multicolumn{10}{|l|}{ Picidae } \\
\hline Dendrocopos syriacus & Alaca Ağaçkakan & Syrian Woodpecker & LC & - & II & - & Y & A. 2 & + \\
\hline Jynx torquilla & Boyunçeviren & Eurasian Wryneck & $\mathrm{LC}$ & - & II & - & $\mathrm{KZ}$ & A.1.2 & - \\
\hline \multicolumn{10}{|l|}{ Passeriformes } \\
\hline Alaudidae & & & & & & & & & \\
\hline Melanocorypha calandra & Boğmaklı Toygar & Calandra Lark & LC & - & II & - & Y & A.5 & + \\
\hline Melanocorypha bimaculata & $\begin{array}{l}\text { Küçük Boğmaklı } \\
\text { Toygar }\end{array}$ & Bimaculated Lark & $\mathrm{LC}$ & - & II & - & G & A. 3 & + \\
\hline Calandrella rufescens & Çorak Toygarı & Lesser Short-toed Lark & $\mathrm{LC}$ & - & II & - & $\mathrm{Y}$ & A. 3 & + \\
\hline Galerida cristata & Tepeli Toygar & Crested Lark & LC & - & III & I & Y & A. 3 & + \\
\hline Lullula arborea & Orman Toygarı & Woodlark & LC & - & III & I & G & A. 3 & - \\
\hline Alauda arvensis & Tarlakuşu & Eurasian Skylark & $\mathrm{LC}$ & - & III & $\mathrm{I}$ & G & A. 4 & + \\
\hline Hirundinidae & & & & & & & & & \\
\hline Riparia riparia & Kum Kırlangicı & Sand Martin & LC & - & II & - & G & A. 5 & + \\
\hline Ptyonoprogne rupestris & Kaya Kırlangıcı & Eurasian Crag Martin & $\mathrm{LC}$ & - & II & - & G & A. 5 & - \\
\hline Hirundo rustica & Kır Kırlangıcı & Barn Swallow & $\mathrm{LC}$ & - & II & - & G & A. 5 & + \\
\hline Delichon urbicum & Ev Kırlangıcı & Common House Martin & $\mathrm{LC}$ & - & II & - & G & A. 3 & + \\
\hline Motacillidae & & & & & & & & & \\
\hline Anthus campestris & Kır İncirkuşu & Tawny Pipit & $\mathrm{LC}$ & - & II & - & G & A. 2 & - \\
\hline Anthus trivialis & Ağaç İncirkuşu & Tree Pipit & $\mathrm{LC}$ & - & II & - & $\mathrm{T}$ & A. 3 & - \\
\hline Anthus pratensis & Çayır İncirkuşu & Meadow Pipit & NT & - & II & - & $\mathrm{T}$ & A. 3 & - \\
\hline Anthus spinoletta & Dağ İncirkuşu & Water Pipit & LC & - & II & - & G & A. 3 & - \\
\hline Motacilla flava & Sarı Kuyruksallayan & Western Yellow Wagtail & LC & - & II & - & G & A.3.1 & + \\
\hline Motacilla flava feldegg & $\begin{array}{l}\text { Maskeli Sarı } \\
\text { Kuyruksallayan }\end{array}$ & Western Yellow Wagtail & - & - & II & - & G & A.3.1 & + \\
\hline Motacilla citreola & $\begin{array}{l}\text { Sarıbaşlı } \\
\text { Kuyruksallayan }\end{array}$ & Citrine Wagtail & LC & - & II & - & G & A. 2 & + \\
\hline Motacilla cinerea & Dağ Kuyruksallayanı & Grey Wagtail & $\mathrm{LC}$ & - & II & - & G & A. 2 & + \\
\hline Motacilla alba & Ak Kuyruksallayan & White Wagtail & $\mathrm{LC}$ & - & II & - & $\mathrm{Y}$ & A.3.1 & + \\
\hline Cinclidae & & & & & & & & & \\
\hline Cinclus cinclus & Derekuşu & White-throated Dipper & LC & - & II & - & Y & A.1.2 & - \\
\hline Troglodytidae & & & & & & & & & \\
\hline Troglodytes troglodytes & Çitkuşu & Eurasian Wren & LC & - & II & - & Y & A.1.2 & - \\
\hline
\end{tabular}


Tablo 1 (devam)

\begin{tabular}{|c|c|c|c|c|c|c|c|c|c|}
\hline Bilimsel Adı & Türkçe Adı & İngilizce Adı & IUCN & CITES & BERN & МАКK & $\begin{array}{l}\text { Bölge } \\
\text { Statü }\end{array}$ & RDB & Üreme \\
\hline \multicolumn{10}{|l|}{ Muscicapidae } \\
\hline Muscicapa striata & Benekli Sinekkapan & Spotted Flycatcher & $\mathrm{LC}$ & - & II & - & $\mathrm{T}$ & A.3 & - \\
\hline \multicolumn{10}{|l|}{ Turdidae } \\
\hline Cercotrichas galactotes & Kızıl Çalıbülbülü & Rufous Bush Chat & LC & - & II & - & G & A. 3 & - \\
\hline Erithacus rubecula & Kizılgerdan & European Robin & $\mathrm{LC}$ & - & II & - & Y & A.3 & - \\
\hline Luscinia megarhynchos & Bülbül & Common Nightingale & LC & - & II & - & $\mathrm{T}$ & A. 2 & - \\
\hline Cyanecula svecica & Buğdaycıl & Bluethroat & LC & - & II & - & Y & A. 2 & + \\
\hline Irania gutturalis & Taş Bülbülü & White-throated Robin & $\mathrm{LC}$ & - & II & - & G & A.1 & - \\
\hline Phoenicurus ochruros & Kara Kızılkuyruk & Black Redstart & $\mathrm{LC}$ & - & II & - & G & A. 2 & - \\
\hline Phoenicurus phoenicurus & Kızılkuyruk & Common Redstart & LC & - & II & - & G & A. 3 & + \\
\hline Saxicola rubetra & Çayır Taşkuşu & Whinchat & $\mathrm{LC}$ & - & II & - & G & A. 3 & + \\
\hline Saxicola torquatus & Taşkuşu & European Stonechat & LC & - & II & - & G & A. 3 & + \\
\hline Oenanthe isabellina & Boz Kuyrukkakan & Isabelline Wheatear & LC & - & II & I & G & A. 3 & + \\
\hline Oenanthe oenanthe & Kuyrukkakan & Northern Wheatear & $\mathrm{LC}$ & - & II & I & G & A. 3 & + \\
\hline Oenanthe pleschanka & Alaca Kuyrukkakan & Pied Wheatear & $\mathrm{LC}$ & - & II & - & $\mathrm{T}$ & A.1.2 & - \\
\hline Oenanthe hispanica & $\begin{array}{l}\text { Karakulaklı } \\
\text { Kuyrukkakan }\end{array}$ & Black-eared Wheatear & $\mathrm{LC}$ & - & II & - & G & A. 2 & - \\
\hline Oenanthe finschii & Aksırtlı Kuyrukkakan & Finsch`s Wheatear & $\mathrm{LC}$ & - & II & - & G & A.1.2 & - \\
\hline Monticola saxatilis & Taşkızılı & Common Rock Thrush & $\mathrm{LC}$ & - & II & - & G & A.1.2 & - \\
\hline Monticola solitarius & Gökardıç & Blue Rock Thrush & $\mathrm{LC}$ & - & II & - & G & A.1.2 & - \\
\hline Turdus torquatus & Boğmaklı Ardıç & Ring Ouzel & $\mathrm{LC}$ & - & II & - & Y & A.1.2 & - \\
\hline Turdus merula & Karatavuk & Common Blackbird & $\mathrm{LC}$ & - & III & II & Y & A.3 & - \\
\hline \multicolumn{10}{|l|}{ Sylviidae } \\
\hline Cettia cetti & Kamış Bülbülü & Cetti`s Warbler & LC & - & II & - & G & A. 2 & - \\
\hline Locustella luscinioides & Bataklık Kamışçını & Savi`s Warbler & LC & - & II & - & G & A. 2 & + \\
\hline Acrocephalus palustris & Çalı Kamış̧̧ını & Marsh Warbler & LC & - & II & - & G & A. 3 & - \\
\hline $\begin{array}{l}\text { Acrocephalus } \\
\text { arundinaceus }\end{array}$ & Büyük Kamışçın & Great Reed Warbler & $\mathrm{LC}$ & - & II & - & G & A. 3 & - \\
\hline Iduna pallida & Ak Mukallit & $\begin{array}{l}\text { Eastern Olivaceous } \\
\text { Warbler }\end{array}$ & LC & - & II & - & G & A. 3 & - \\
\hline Sylvia nisoria & Çizgili Ötleğen & Barred Warbler & LC & - & II & - & $\mathrm{T}$ & A. 2 & - \\
\hline Sylvia borin & Boz Ötleğen & Garden Warbler & $\mathrm{LC}$ & - & II & - & $\mathrm{T}$ & B.3 & - \\
\hline Phylloscopus collybita & Çıvgın & Common Chiffchaff & $\mathrm{LC}$ & - & II & - & G & A.3.1 & + \\
\hline Phylloscopus trochilus & Söğüt Bülbülü & Willow Warbler & $\mathrm{LC}$ & - & II & - & $\mathrm{T}$ & A.3.1 & - \\
\hline \multicolumn{10}{|l|}{ Panuridae } \\
\hline Panurus biarmicus & Bıyıklı Baştankara & Bearded Reedling & LC & - & II & - & $\mathrm{KZ}$ & A.3 & - \\
\hline \multicolumn{10}{|l|}{ Paridae } \\
\hline Cyanistes caeruleus & Mavi Baştankara & Eurasian Blue Tit & LC & - & II & - & Y & A. 2 & - \\
\hline Parus major & Büyük Baştankara & Great Tit & $\mathrm{LC}$ & - & II & - & Y & A.3.1 & + \\
\hline \multicolumn{10}{|l|}{ Sittidae } \\
\hline Sitta neumayer & Kaya Sivacısı & Western Rock Nuthatch & $\mathrm{LC}$ & - & II & - & Y & A. 2 & - \\
\hline \multicolumn{10}{|l|}{ Remizidae } \\
\hline Remiz pendulinus & Çulha Kuşu & Eurasian Penduline Tit & $\mathrm{LC}$ & - & III & - & $\mathrm{Y}$ & A. 2 & - \\
\hline \multicolumn{10}{|l|}{ Laniidae } \\
\hline Lanius collurio & $\begin{array}{l}\text { Kızıl Sırtlı Örümcek } \\
\text { Kuşu }\end{array}$ & Red-backed Shrike & LC & - & II & I & G & A. 3 & + \\
\hline Lanius minor & $\begin{array}{l}\text { Kara Alınlı Örümcek } \\
\text { Kuşu }\end{array}$ & Lesser Grey Shrike & $\mathrm{LC}$ & - & II & - & G & A.3 & - \\
\hline Lanius excubitor & Büyük Örümcek Kuşu & Great Grey Shrike & $\mathrm{LC}$ & - & II & - & $\mathrm{KZ}$ & A.1.2 & - \\
\hline Lanius senator & $\begin{array}{l}\text { Kızıl Başlı Örümcek } \\
\text { Kuşu }\end{array}$ & Woodchat Shrike & $\mathrm{LC}$ & - & II & - & G & A. 2 & - \\
\hline \multicolumn{10}{|l|}{ Corvidae } \\
\hline Garrulus glandarius & Alakarga & Eurasian Jay & LC & - & - & II & Y & A.3.1 & + \\
\hline Pica pica & Saksağan & Eurasian Magpie & $\mathrm{LC}$ & - & - & II & Y & A. 5 & + \\
\hline Pyrrhocorax pyrrhocorax & Kızılgagalı Dağ Kargası & Red-billed Chough & $\mathrm{LC}$ & - & II & - & Y & A. 3 & - \\
\hline Corvus monedula & Küçük Karga & Western Jackdaw & LC & - & - & II & Y & A. 5 & + \\
\hline Corvus frugilegus & Ekin Kargası & Rook & $\mathrm{LC}$ & - & - & II & Y & A. 5 & + \\
\hline Corvus cornix & Leş Kargası & Hooded Crow & - & - & - & - & Y & A. 5 & + \\
\hline Corvus corax & Kuzgun & Northern Raven & LC & - & III & I & Y & A. 5 & - \\
\hline \multicolumn{10}{|l|}{ Sturnidae } \\
\hline Sturnus vulgaris & Sığırcık & Common Starling & $\mathrm{LC}$ & - & - & I & Y & A. 5 & + \\
\hline Pastor roseus & Alası̆̆ırcık & Rosy Starling & LC & - & II & - & G & A. 4 & - \\
\hline
\end{tabular}


Tablo 1 (devam)

\begin{tabular}{|c|c|c|c|c|c|c|c|c|c|}
\hline Bilimsel Adı & Türkçe Adı & İngilizce Adı & IUCN & CITES & BERN & МАКК & $\begin{array}{l}\text { Bölge } \\
\text { Statü }\end{array}$ & RDB & Üreme \\
\hline \multicolumn{10}{|l|}{ Passeridae } \\
\hline Passer domesticus & Ev Serçesi & House Sparrow & $\mathrm{LC}$ & - & - & II & Y & A. 5 & + \\
\hline Petronia petronia & Kaya Serçesi & Rock Sparrow & $\mathrm{LC}$ & - & II & - & Y & A. 3 & - \\
\hline \multicolumn{10}{|l|}{ Fringillidae } \\
\hline Fringilla coelebs & İspinoz & Common Chaffinch & $\mathrm{LC}$ & - & III & I & Y & A. 4 & - \\
\hline Fringilla montifringilla & Dağ İspinozu & Brambling & LC & - & III & I & $\mathrm{KZ}$ & A.3 & - \\
\hline Carduelis carduelis & Saka & European Goldfinch & $\mathrm{LC}$ & - & II & - & Y & A.3.1 & + \\
\hline Spinus spinus & Karabaşlı İskete & Eurasian Siskin & $\mathrm{LC}$ & - & II & - & $\mathrm{KZ}$ & A. 3 & - \\
\hline Linaria cannabina & Keten Kuşu & Common Linnet & LC & - & II & - & Y & A. 3 & + \\
\hline Linariaflavirostris & Sarı Gagalı Keten Kuşu & Twite & $\mathrm{LC}$ & - & II & - & Y & A. 3 & - \\
\hline Rhodopechys sanguineus & Kızıl Şakrak & $\begin{array}{l}\text { Eurasian Crimson- } \\
\text { winged Finch }\end{array}$ & $\mathrm{LC}$ & - & III & I & Y & A.3 & - \\
\hline \multicolumn{10}{|l|}{ Emberizidae } \\
\hline Emberiza citrinella & Sarı Kirazkuşu & Yellowhammer & $\mathrm{LC}$ & - & II & - & $\mathrm{KZ}$ & A. 2 & - \\
\hline Emberiza cia & Kaya Kirazkuşu & Rock Bunting & $\mathrm{LC}$ & - & II & - & $\mathrm{Y}$ & A. 2 & - \\
\hline Emberiza hortulana & Kirazkuşu & Ortolan Bunting & $\mathrm{LC}$ & - & III & I & G & A. 3 & + \\
\hline Emberiza schoeniclus & Bataklık Kirazkuşu & Common Reed Bunting & $\mathrm{LC}$ & - & II & - & $\mathrm{KZ}$ & A. 3 & - \\
\hline Emberiza melanocephala & Karabaşlı Kirazkuşu & Black-headed Bunting & $\mathrm{LC}$ & - & II & - & G & A. 4 & + \\
\hline Emberiza calandra & Tarla Kirazkuşu & Corn Bunting & $\mathrm{LC}$ & - & III & I & G & A. 4 & + \\
\hline
\end{tabular}

Tablo 2: Alanda ve yakın çevresinde yaşayan balık, kurbağa, sürüngenler ve memeli türleri

\begin{tabular}{|c|c|c|c|c|c|c|}
\hline Bilimsel Adı & Türkçe Adı & İngilizce Adı & Endemizm & IUCN & CITES & BERN \\
\hline \multicolumn{7}{|l|}{ Actinopterygii } \\
\hline \multicolumn{7}{|l|}{ Cyprinidae } \\
\hline $\begin{array}{l}\text { Alburnus tarichi (Güldenstädt, } \\
\text { 1814) }\end{array}$ & İnci Kefali, Van Balığı & Van Shah Kuli & + & NT & - & - \\
\hline \multicolumn{7}{|l|}{ Amphibia } \\
\hline \multicolumn{7}{|l|}{ Bufonidae } \\
\hline Bufotes variabilis (Pallas, 1769) & Değişken Desenli Gece Kurbağası & Variable Toad & - & DD & - & III \\
\hline \multicolumn{7}{|l|}{ Pelobatidae } \\
\hline Pelobates syriacus Boettger, 1889 & Toprak Kurbağası & $\begin{array}{l}\text { Eastern Spadefoot, Syrian } \\
\text { Spadefoot }\end{array}$ & - & LC & - & II \\
\hline \multicolumn{7}{|l|}{ Ranidae } \\
\hline $\begin{array}{l}\text { Pelophylax ridibundus (Pallas, } \\
\text { 1771) }\end{array}$ & $\begin{array}{l}\text { Ova Kurbağası, Bataklık } \\
\text { Kurbağası }\end{array}$ & $\begin{array}{l}\text { Euroasian Marsh Frog, Marsh } \\
\text { Frog }\end{array}$ & - & LC & - & III \\
\hline \multicolumn{7}{|l|}{ Reptilia (Sürüngenler) } \\
\hline \multicolumn{7}{|c|}{ Geoemydidae (Bataklık Kaplumbağaları) } \\
\hline Mauremys caspica (Gmelin, 1774) & Hazer Çizgili Kaplumbağası & Caspian Turtle & - & - & - & II \\
\hline \multicolumn{7}{|c|}{ Testudinidae (Kara Kaplumbağaları, Tosbağagiller) } \\
\hline Testudo graeca Linnaeus, 1758 & Tosbağa & $\begin{array}{l}\text { Mediterranean Spur-thighed } \\
\text { Tortoise }\end{array}$ & - & VU & II & II \\
\hline \multicolumn{7}{|c|}{ Lacertidae (Eski Dünya Adi Kertenkeleleri) } \\
\hline $\begin{array}{l}\text { Lacerta media Lantz \& Cyrén, } \\
1920\end{array}$ & $\begin{array}{l}\text { Doğu Yeşil Kertenkelesi, Ortanca } \\
\text { Yeşil Kertenkele }\end{array}$ & $\begin{array}{l}\text { Levant Green Lizard, Medium- } \\
\text { sized Green Lizard }\end{array}$ & - & LC & - & III \\
\hline Ophisops elegans Ménétriés, 1832 & $\begin{array}{l}\text { Tarla Kertenkelesi, Yılan Gözlü } \\
\text { Kertenkele }\end{array}$ & Snake-eyed Lizard & - & - & - & II \\
\hline \multicolumn{7}{|l|}{ Colubridae (Kırbaç Yılanları) } \\
\hline $\begin{array}{l}\text { Dolichophis schmidti (Nikolsky, } \\
\text { 1909) }\end{array}$ & Kırmızı Yılan & Schmidt's Whip Snake & - & LC & - & III \\
\hline Natrix tessellata (Laurenti, 1768) & Su Yılanı & $\begin{array}{l}\text { Dice Snake, Tessellated Water } \\
\text { Snake }\end{array}$ & - & LC & - & II \\
\hline \multicolumn{7}{|l|}{ Mammalia } \\
\hline \multicolumn{7}{|l|}{ Canidae } \\
\hline Vulpes vulpes (Linnaeus, 1758) & Kızıl Tilki & Red Fox & - & LC & - & - \\
\hline \multicolumn{7}{|l|}{ Vespertilionidae } \\
\hline $\begin{array}{l}\text { Pipistrellus pipistrellus (Schreber, } \\
\text { 1774) }\end{array}$ & Bayağı cüce yarasa & Common Pipistrelle & - & LC & - & - \\
\hline \multicolumn{7}{|l|}{ Erinaceidae } \\
\hline Erinaceus concolor Martin, 1837 & Kirpi & $\begin{array}{l}\text { Southern White-breasted } \\
\text { Hedgehog }\end{array}$ & - & LC & - & - \\
\hline \multicolumn{7}{|l|}{ Cricetidae } \\
\hline Microtus socialis (Pallas, 1773) & Küçük Tarlafaresi & Social Vole & - & LC & - & - \\
\hline \multicolumn{7}{|l|}{ Muridae } \\
\hline Mus musculus Linnaeus, 1758 & Ev faresi & House Mouse & - & LC & - & - \\
\hline
\end{tabular}


Tablo 3: Alanda bulunan bitkiler. T: Terofit (tek yıllık); Hk: Hemikriptofit (Yarısaklı gövdeli, çok yıllık); Kr: Kriptofit (Gövdesi tamamen toprak veya su içinde, çok yıllık); Ka: Kamefit (çalı formunda, topraktan $40 \mathrm{~cm}$ yüksekte tepe tomurcuğu olan); Fa: Fanerofit (Tepe tomurcuğu 40cm'nin üzerinde genellikle ağaç formundaki bitki); İr.-Tur. elm.; İran-Turan Fitocoğrafik Bölge elementi; Euro-Sib. elm.; Avrupa- Sibirya Fitocoğrafik Bölge elementi.; Euxin elm: Öksin (Avrupa-Sibirya fitocoğrafik) fitocoğrafik alt bölgesi

\begin{tabular}{|c|c|c|c|c|}
\hline Bilimsel Adı & Türkçe Adı & $\begin{array}{l}\text { Hayat } \\
\text { Formu }\end{array}$ & Habitat & Element \\
\hline \multicolumn{5}{|l|}{ Asteraceae } \\
\hline Cota wiedemanniana & Bodur babuçca & $\mathrm{T}$ & Çayır-Kumul & Batı, İç, Güney ve Doğu Anadolu da yaygın \\
\hline Achillea vermicularis & Püşan & $\mathrm{Hk}$ & Çayır & Doğu Anadolu da yaygın \\
\hline Achillea millefolium subsp. millefolium & Civanperçemi & $\mathrm{Hk}$ & Çayır & Euro-Sib Elm. \\
\hline Crepis sancta & Yaban kıskısı & $\mathrm{T}$ & Ruderal & Geniş yayılışlı \\
\hline Circium arvense subsp. arvense & Köygöçüren & $\mathrm{Hk}$ & $\begin{array}{l}\text { Çayır-Su } \\
\text { Kenarı }\end{array}$ & Geniş yayılışlı \\
\hline Rhagadiolus angulosus & Katlak çanak & $\mathrm{T}$ & Çayır-Kumul & İr.-Tur. Elm. \\
\hline Koelpinia linearis & Kaşgaldak & $\mathrm{T}$ & Çayır-Kumul & İr.-Tur. Elm. \\
\hline Centaurea virgata & Acı süpürge & $\mathrm{T}$ & Ruderal & Geniş yayılışlı \\
\hline Centaurea solsitialis subsp. solsitialis & Çakırdikeni & $\mathrm{T}$ & Ruderal & Geniş yayılışlı \\
\hline Xeranthemum annuum & Kâğıt çiçeği & $\mathrm{T}$ & Ruderal & Geniş yayılışlı \\
\hline Tripleurospermum parviflorum & Beybunik & $\mathrm{T}$ & Çayır & Geniş yayılışlı \\
\hline Scorzonera parviflora & Çatal kök & $\mathrm{Kr}$ & Çayır & $\begin{array}{l}\text { İç Anadlo Bölgesi ve Doğu Anadolu Bölgesinde } \\
\text { yayılışı var }\end{array}$ \\
\hline $\begin{array}{l}\text { Tragopogon buphthalmoides var. } \\
\text { buphthalmoides }\end{array}$ & Tarla yemliği & $\mathrm{Kr}$ & Çayır & İr.-Tur. elm. \\
\hline Onopordum acanthium & Galagan & $\mathrm{Hk}$ & Çayır & Geniş yayılışlı \\
\hline Senecio vernalis & Kanaryaotu & $\mathrm{T}$ & Çayır & Geniş yayılışlı \\
\hline Lactuca scarioloides & Meloto marulu & $\mathrm{Hk}$ & Çayır & İr.-Tur. elm. \\
\hline \multicolumn{5}{|l|}{ Boraginaceae } \\
\hline Alkanna orientalis var. orientalis & Sarı sormuk & $\mathrm{Hk}$ & Çayır & $\begin{array}{l}\text { Kuzeybatı, Güney batı ve İç Anadolu da yayılış } \\
\text { gösterir }\end{array}$ \\
\hline Anchusa azurea var. azurea & Sığırdili & $\mathrm{Hk}$ & Çayır & Geniş yayılışlı \\
\hline \multicolumn{5}{|l|}{ Brassicaceae } \\
\hline Brassica oleracea & Lahana & $\mathrm{T}$ & Çayır & Geniş yayılışlı \\
\hline Goldbachia laevigata & Gagalı hardal & $\mathrm{T}$ & Çayır & İr.- Tur. elm. \\
\hline Alyssum simplex & Sade kuduzotu & $\mathrm{T}$ & Çayır & Geniş yayılışlı \\
\hline Alyssum strigosum subsp. strigosum & Dökük kuduzotu & $\mathrm{T}$ & Çayır & Geniş yayılışlı \\
\hline Clypeola jonthlaspi & Akçeotu & $\mathrm{T}$ & Çayır & Geniş yayılışlı \\
\hline Euclidium syriacum & Findık hardalı & $\mathrm{T}$ & Çayır & Geniş yayılışlı \\
\hline Strigosella africana & Keçe teresi & $\mathrm{T}$ & Çayır & Geniş yayılışlı \\
\hline Erysimum crassipes & Zarifeotu & $\mathrm{Hk}$ & Çayır & Geniş yayılışlı \\
\hline Sisymbrium orientale & Tarla bülbülotu & $\mathrm{T}$ & Çayır & Geniş yayılışlı \\
\hline \multicolumn{5}{|l|}{ Caryophyllaceae } \\
\hline Minuartia hybrida subsp. turcica & Ekin tıs tısı & $\mathrm{T}$ & Çayır & Geniş yayılışlı \\
\hline Minuartia meyeri & Koza tistısı & $\mathrm{T}$ & Çayır & İr.-Tur. Elm. \\
\hline Vaccaria hispanica & Ekin ebesi & $\mathrm{T}$ & Çayır & Geniş yayılışlı \\
\hline \multicolumn{5}{|l|}{ Chenopodiaceae } \\
\hline Chenopodium album subsp. album & Aksirken & $\mathrm{T}$ & Çayır & Geniş yayılışlı \\
\hline Salsola kali & Döngele & $\mathrm{T}$ & Çayır & Geniş yayılışlı \\
\hline \multicolumn{5}{|l|}{ Cistaceae } \\
\hline Helianthemum ledifolium var. ledifolium & Kuru gün gülü & $\mathrm{T}$ & Çayır & Geniş yayılışlı \\
\hline \multicolumn{5}{|l|}{ Cyperaceae } \\
\hline Carex medwedewii & Ova sazotu & $\mathrm{Hk}$ & Çayır & Geniş yayılışlı \\
\hline Carex leporina & Tülü sazotu & $\mathrm{Hk}$ & Çayır & Geniş yayılışlı \\
\hline Eleocharis uniglumis & Kapçık sazı & $\mathrm{Kr}$ & Çayır & Geniş yayılışlı \\
\hline Bollboscschoenus maritimus subsp. maritimus & Sandelye sazı & $\mathrm{Kr}$ & Su kenarı & Geniş yayılışlı \\
\hline Schoenoplectus tabernaemontani & Ayna semerotu & $\mathrm{Kr}$ & Su kenarı & Geniş yayılışlı \\
\hline \multicolumn{5}{|l|}{ Euphorbiaceae } \\
\hline Euphorbia orientalis & Gezer sütleğen & $\mathrm{Hk}$ & Çayır & İr.-Tur. Elm. \\
\hline \multicolumn{5}{|l|}{ Fabaceae } \\
\hline Medicago monantha & Dağ guniği & $\mathrm{T}$ & Çayır & İr.-Tur. Elm. \\
\hline Trigonella coerulescens subsp. coerulescens & Hint kokası & $\mathrm{T}$ & Çayır & İr.-Tur. Elm. \\
\hline Medicago minima var. minima & Gurnik & $\mathrm{T}$ & Çayır & Geniş yayılışlı \\
\hline Melilotus officinalis & Kokulu yonca & $\mathrm{Hk}$ & Çayır & Geniş yayılışlı \\
\hline Lotus corniculatus var. tenuifolia & Gazal boynuzu & $\mathrm{Hk}$ & Çayır & Geniş yayılışlı \\
\hline Trifolium pratense var. pratense & Çayır üçgülü & $\mathrm{Hk}$ & Çayır & Geniş yayılışlı \\
\hline
\end{tabular}


Tablo 3 (devam)

\begin{tabular}{|c|c|c|c|c|}
\hline Bilimsel Adı & Türkçe Adı & $\begin{array}{l}\text { Hayat } \\
\text { Formu }\end{array}$ & Habitat & Element \\
\hline \multicolumn{5}{|l|}{ Geraniaceae } \\
\hline Erodium cicutarium subsp. cicutarium & İğnelik & $\mathrm{T}$ & Çayır & Geniş yayılışlı \\
\hline \multicolumn{5}{|l|}{ Juncacea } \\
\hline Juncus inflexus & Sazak & $\mathrm{Kr}$ & Su kenarı & Geniş yayılışlı \\
\hline Juncus gerardi subsp. libanoticus & Erkek kofa & $\mathrm{Kr}$ & Su kenarı & Geniş yayılışlı \\
\hline \multicolumn{5}{|l|}{ Lamiaceae } \\
\hline Mentha longifolia subsp. longifolia & Pünk & $\mathrm{Hk}$ & $\begin{array}{l}\text { Su kenarı- } \\
\text { Çayır }\end{array}$ & $\begin{array}{l}\text { Euro Sib. Elm } \\
\text { (Euxin elm.) }\end{array}$ \\
\hline \multicolumn{5}{|l|}{ Malvaceae } \\
\hline Malva neglecta & Çoban çöreği & $\mathrm{T}$ & Çayır & Geniş yayılışlı \\
\hline \multicolumn{5}{|l|}{ Papaveraceae } \\
\hline Papaver rhoeas & Gelincik & $\mathrm{T}$ & Çayır & Geniş yayıllışlı \\
\hline Fumaria acepala & Şahtere & $\mathrm{T}$ & Kumul-Çayır & İr.-Tur. Elm. \\
\hline \multicolumn{5}{|l|}{ Plantaginaceae } \\
\hline Plantago lanceolata & Damarlica & $\mathrm{Hk}$ & Kumul-Çayır & Geniş yayıllışlı \\
\hline \multicolumn{5}{|l|}{ Poaceae } \\
\hline Taeniatherum çaput-medusae subsp. crinitum & Kılçık arpası & $\mathrm{T}$ & Çayır & Geniş yayılışlı \\
\hline Heteranthelium piliferum & Çorakarpası & $\mathrm{T}$ & Çayır & İr.-Tur. elm. \\
\hline Aegilops triuncialis subsp. triuncialis & Üç kılçık & $\mathrm{T}$ & Çayır & Geniş yayılışlı \\
\hline Hordeum brevisubulatum subsp. violaceum & Çayır arpası & $\mathrm{Hk}$ & Çayır & İr.-Tur. elm. \\
\hline Alopecurus arundinaceus & $\begin{array}{l}\text { Kamış } \\
\text { tilkikuyruğu }\end{array}$ & $\mathrm{Hk}$ & Çayır & Geniş yayılışlı \\
\hline Alopecurus textilis subsp. textilis & $\begin{array}{l}\text { Saçaklı } \\
\text { tilkikuyruğu }\end{array}$ & $\mathrm{Hk}$ & Çayır & İr.-Tur. elm. \\
\hline Puccinella distans subsp. sevangensis & Kaf tuzçimi & $\mathrm{Hk}$ & $\begin{array}{l}\text { Su kenar1- } \\
\text { Çayır }\end{array}$ & Geniş yayılışlı \\
\hline Bromus tectorum subsp. tectorum & Kır bromu & $\mathrm{T}$ & Çayır & Geniş yayılışlı \\
\hline Bromus danthoniae subsp. danthoniae & İbubuk otu & $\mathrm{T}$ & Çayır & Geniş Yayılışlı \\
\hline Henrardia persica var. persica & Acem kuyrukotu & $\mathrm{T}$ & Çayır & İr.-Tur. Elm. \\
\hline Poa pratense & Çayır salkımotu & $\mathrm{Kr}$ & Çayır & Geniş yayılışlı \\
\hline Cynodon dactylon var. villosus & Köpek dişi & $\mathrm{Hk}$ & Çayır & Geniş yayıllışlı \\
\hline Phragmites australis & Kamış & $\mathrm{Hk}$ & Su kenarı & Geniş yayılışlı \\
\hline \multicolumn{5}{|l|}{ Polygonacea } \\
\hline Rumex angustifolius subsp. angustifolius & Taş turşusu & $\mathrm{Hk}$ & Çayır & İr.-Tur. Elm. \\
\hline \multicolumn{5}{|l|}{ Potamogetonaceae } \\
\hline $\begin{array}{l}\text { Stuckenia pectinata (Sin :Potamogetom } \\
\text { pectinatum) }\end{array}$ & Sutarağ 1 & $\mathrm{Kr}$ & Su İçi & Geniş yayılışlı \\
\hline \multicolumn{5}{|l|}{ Primulaceae } \\
\hline Androsace maxima & Tavuk kursağı & $\mathrm{T}$ & Çayır & Geniş yayılışlı \\
\hline \multicolumn{5}{|l|}{ Ranunculaceae } \\
\hline Adonis flammea & Cin lalesi & $\mathrm{T}$ & Çayır & Geniş yayılışlı \\
\hline Consolida orientalis & Mor çiçek & $\mathrm{T}$ & Çayır & Geniş yayılışlı \\
\hline Ranunculus arvensis & Mustafa çiçeği & $\mathrm{T}$ & Ruderal & Geniş yayılışlı \\
\hline Ranunculus sceleratus & Batak düğünçiçeği & $\mathrm{T}$ & Su kenarı & Geniş yayılışlı \\
\hline \multicolumn{5}{|l|}{ Resedaceae } \\
\hline Reseda lutea var. lutea & Muhabbet çiçeği & $\mathrm{Hk}$ & Ruderal & Geniş yayılışlı \\
\hline \multicolumn{5}{|l|}{ Salicaceae } \\
\hline Salix babyllonica & Salkım söğüt & $\mathrm{Fa}$ & Su kenarı & Kültür \\
\hline \multicolumn{5}{|l|}{ Scrophulariaceae } \\
\hline Veronica anagallis-aquatica & Sugedemesi & $\mathrm{Hk}$ & Su kenarı & Geniş yayılışlı \\
\hline \multicolumn{5}{|l|}{ Solanaceae } \\
\hline Hyoscyamus niger & Banotu & $\mathrm{T}$ & Ruderal & Geniş yayılışlı \\
\hline \multicolumn{5}{|l|}{ Thyphaceae } \\
\hline Thpha angustifolia & Saz & $\mathrm{Kr}$ & Su kenarı & Geniş yayılışlı \\
\hline \multicolumn{5}{|l|}{ Zygophyllaceae } \\
\hline Tribulus terestris & Çoban çökerten & $\mathrm{T}$ & Ruderal & Geniş yayılışlı \\
\hline
\end{tabular}


habitatlarda gece aktif olarak gözlenmiştir (Tablo 2). Su Yılanı (Natrix tessellata) ve Hazer Çizgili kaplunmağası (Mauremys caspica) Sazlığa dökülen tatlı su kaynaklarının kenarında güneşlenirken, diğer sürüngen türleri de yakındaki karasal habitatlarda tespit edilmiştir (Tablo 2).Memeli (Mammalia) sınıfında alanda en çok göze çarpan Kızıl tilki (Vulpes vulpes) türüdür. Ayrıca Küçük tarla faresi (Microtus socialis), Ev faresi (Mus musculus), Kirpi (Erinaceus concolor)ve Bayağı cüce yarasa (Bayağ1 cüce yarasa) alandaki diğer memelilerdir.

\subsection{Floristik sonuçlar}

Yapilan incelemeler sonucunda alanda 79 adet bitki taksonu tespit edilmiştir (Tablo 3). Tespit edilen bitkilerin daha ziyade sucul alan bitkisi olduğu dikkat çekmektedir. Alanda tespit edilen bitkilerden 58'i geniş yayılışlı (kozmopolit)'dır. Geri kalan 21 bitki taksonundan 14'ü İran-Turan Fitocoğrafik Bölge elementi, 2'i Euro-Siberian Fitocoğrafik Bölge elementi, 1'i kültür formudur. 4 türün ise Doğu Anadolu Bölgesi başta olmak üzere birçok alanda yayılışı bulunmaktadır. Alanımızda endemik bitki yer almamaktadir.

Van Sazlığının bitki yaşamı açısından habitatları sınıflandırılırken bitkilerin su ile ilişkileri esas alınmıştır. Dolayısıyla su içi, su kenarı, tabansuyu bulunan (çayır), su ile sazlıklar arasında şerit halinde bulunan kumul alanlar, suya teması mevsime bağlı olan ve genellikle kozmopolit, döküntü alanlarda yayılış gösteren ruderal olarak adlandırılan habitatlardan oluşmaktadır (Tablo 3).

\section{Tartışma}

Van Gölü Havzası için Vielliard (1968) 111, Kumerlove (1969) ise 219 kuş türü rapor etmiştir. Van sazlığında yaşayan kuş türleri hakkında çeşitli çalışmalar yapılmıştır (Anonim 1193, Adizel 1998, Van den Berk ve ark. 1993). Schilperoord ve Schilperoord-Huisman (1986) tarafından, çalışma sahası içinde kalan Van iskelesi ile Edremit girişi arasından 29 tür rapor edilmiştir. Kasparek (1989) Edremit Sazlığını, Toy kuşu ve Mezgeldek türlerinin bulunduğu alanlar içinde göstermiştir. Van den Berk ve ark. (1993) Güney Van Sazlığı olarak adlandırdıkları Edremit Sazlıkları́nda 71 kuş türünü rapor etmiştir. Nesli tehlike altında olan Dikkuyruk türünün en az 15-20 çiftinin Edremit Sazlıklarında ürediği rapor edilmiştir (Kılıç ve Eken 2004). Bu çalışma ile Van Sazlığında 185 kuş türünün bulunduğu tespit edilmiştir. Alan hayvan çeşitliliği bakımından incelendiğinde kuş türlerinin daha çok ön planda olduğu görülür. Sahanın özellikle yaban ördekleri için havadaki önemli bir üreme ve barınma noktası olduğu aşikardır. Bu ördeklerden birisi olan Dikkuyruk IUCN kriterlerine göre küresel ölçekte soyu tükenme tehlikesi altında bulunan ve alanda üreyen bir türdür. Öte taraftan çalışma sahasında gözlenen Bozkır Delicesi, Çamur Çulluğu, Kervan Çulluğu ve Gök Kuzgun türleri de küresel ölçekte tehlike sınırında olan türlerdir. Alanda tespit edilen kuşlardan 138'i sahada veya yakın bir alanda üremektedir. Kasparek (1989)'in yaptığı çalışmada ve yöre insanının da ifadeleri ile yakın geçmişe kadar azalan bir ivme ile Toy kuşu ile Mezgeldek türlerinin alanda varlığı bilinmektedir. Fakat son on yılda bu türlerin alanda olduğuna dair bir bulgu mevcut değildir. Ayrıca yukarıda bahsi geçen çalışmalarda belirtilen türlerden yaz ördeği (Marmaronetta angustirostris) dışında bütün türler çalışmamızda da tespit edilmiştir. Van gölünde yaşayan tek balık türü Alburnus tarichi (Van Balığı)'dir (Arabacı ve Sarı 2004). Van Sazlığı'nda da A. tarichi dışında bir balık türü gözlenmemiştir. Diğer fauna elemanları hakkında doğrudan alanda yapılan bir çalışma olmamakla birlikte, çalışma sahasına yakın bölgelerden Bufotes variabilis, Pelophylax ridibundus, Lacerta media, Dolicophis schmidti ve Natrix tessellata rapor edilmiştir (Mulder, 1995, Baran ve Atatür 1998). Bu çalışmada bu türlere ilaveten Pelobates syriacus, Ophisops elegans, Mauremys caspica ve Testudo greaca alanda tespit edilen türlerdir.

Alan, bitki yaşamı bakımından hidrofit ve mezofit bitkilerinin yayılış gösterdiği sulak alan sınıfına girmektedir. Alanın doğal peyzaj elemanlarının korunarak kullanılabilmesi için alanın göl sınırını kapatarak suyun durgunlaşmasına ve üzerinde step ve kozmopolit bitki elemanlarının yetişmesine vasıta olan dolgu faaliyetlerinin bir an önce sonlandırılması ve bu alanların rehabilitasyonunun yapılması gerekmektedir. Alanın sucul bitki örtüsü ile kaplı alanlarından su içi vejetasyona güzel bir örnek Potametum pectinati birliğidir. (Behçet 1994). Bu etkilerle birlikte göl kenarı dolgu alanları üzerinde kozmopolit ve step elemanları da alanda varlığını göstermektedir. Yolun göle bakan kesimlerinde kserofit (kurakçıl) karakterli bitki örtüsü ile gölün sahil kumulları ile yol arasında kalan kıyı kesimlerinde yer yer Pragmites australis (kamış) bitki toplulukları görülmektedir. Alanımız içerisinde sahil kumullarının içerisinde psammofit (kumul) bitki örtüsü olarak adlandırılan bitkiler de gelişmiştir. Bu bitkilerden en tipik ve geniş yayılışlı olanı Salsola kali'dir. Behçet ve Altan (1994) Van Sazlığı'nının da aralarında yer aldığı havzadaki sulak alanlarda görülen bitki türlerini rapor etmiştir. Zeyrek ve Öztürk (1993) Van Sazlığı'nın doğu sınırı içinde kalan Van Kalesi florasını araştırmıştır. Araştırmacılar incelemelerinde sucul alanlar için 53 bitki taksonu bildirmiştir (Zeyrek ve Öztürk 1993). Bu çalışma sonucunda alanda 79 bitki taksonu belirlenmiştir. Ayrıca alanda bulunan bitki taksonlarından 1 Fanerofit, 10 Kriptofit, 25 Hemikriptofit geri kalan 43 adet bitki taksonu ise Terofit hayat formuna sahiptir. Bir alanin bitki örtüsünün sağlıklı sıralı gelişimine (süksesyon) gösterge olarak alınabilecek olan odunsu ve alanda kalıcı bir şekilde kök ve gövde yapısına sahip fanerofit, kamefit ve hemikriptofit bitkiler alanda oldukça az bulunmaktadır. Dolayısı ile alanın kararlı bir bitki örtüsüne sahip olmadığı tespit edilmiştir. Bununla birlikte bitki yaşamı açısından öncü diyebileceğimiz tek yıllık bitkilerin alanda çoklukla yayılış göstermesi alanın sürekli hareket halinde olduğu ve alana toprak taşındığını ve kararlı bir ekolojik görüntüye ve dolayısıyla özel bir bitki örtüsüne sahip olmadığını göstermektedir. Alandaki bitkiler çoğunlukla kozmopolit türlerden oluşmaktadır. Bu durum, alanın gelişimi hakkında bilgiler vermektedir. Dolayısı ile bu alanın yeni bir alan olduğu ve kozmopolit bitkiler tarafından istilaya uğradığını söylemek mümkündür. Habitatın yeni bir alan gibi görünmesinin bir nedeni son yillarda yaşanan su yükselmeleri olabilir. Acı göl suyu yükselme sonucu karasal tatlı sucul ortamları basarak zarar vermektedir. Alanın sulak kesimlerinde de tabansuyu yüksek olan hidrofit (suyu seven) ve mezofit (suya orta derecede ihtiyaç duyan) bitkiler yoğunluktadır. Karaya doğru nispeten step elemanı diyebileceğimiz kserofit (kurak 
alanları tercih eden) karakterli bitkiler tespit edilmiştir. Sulak kesimler dışında kalan saha tarım alanı olarak kullanılmaktadır. Tarım ve hayvancılık faaliyetleri alanın doğal bitki varlığını büyük oranda zayıflatmıştır.

Çalışma alanın karakteri sulak alan ekosistemidir. Ekosistem içinde acı su, tatlı su, kumul, lagün, sazlık, ıslak çayır, tarla ve ağaçlık habitatlar bulunmaktadır. Ekosistemin sulak alan karakterinin çeşitli baskılar sonucu hızla zayıfladığı açıkça görülmektedir. Hatta sistem yer yer tamamen tahrip olmuş durumdadır. Alanın geçmiş doğal eşiklerine bakıldığında, sulak alanın büyük oranda yok olduğu kolaylıkla görülür. Baskılar sonucu alanın bütünlügüü büyük oranda parçalanmış durumdadır. Van Sazlığı büyük oranda yapılaşma baskısı altındadır. Alandaki insan aktiviteleri doğal yapıya zarar vermektedir. Drenaj ve dolgu çalışmaları sürekli olarak alanın sınırlarının daralmasına neden olmaktadır. Av, tarım, kirlilik ve yol açma çalışmaları alanın karekterini olumsuz etkilemektedir. Baskılar diğer canlı türlerini de olumsuz etkilemektedir. Av hayvanları yanında sahada insanlar tarafından öldürülmüş çok sayıda yılan ve tilki görmek mümkündür.

Sonuç olarak bu çalışma ile Van Sazlığı'nda 1 balık, 3 kurbağa, 6 sürüngen, 5 memeli ve 185 kuş türü olmak üzere 200 fauna elemanı ve 79 flora elemanı tespit edilerek ilk kez alanın tür biyoçeşitliliği belirlenmiştir. Alanın sahip olduğu tür çeşitliliği, birçok canlı türünün üreme ve beslenme sahası olmasindan dolayı korunması gerekliliğini ortaya koymaktadır.

Teşekkür: Bu çalışmanın bir bölümü, Orman ve Su İşleri Bakanlığı, Doğa Koruma ve Milli Parklar Genel Müdürlüğü tarafından yürütülen "Van İlinin Karasal Biyolojik Çeşitlilik ve İçsu Ekosistemleri Biyolojik Çeşitlilik ve Envanter ve İzleme Projesi" ve Çevre ve Şehircilik Bakanlığı tarafından yürütülen, "Van, Bitlis, Hakkâri, Muş, Siirt ve Şırnak İlleri Doğal Sit Alanlarının Ekolojik Temelli Bilimsel Araştırma Projesi" kapsamında gerçekleştirilmiştir.

\section{Kaynaklar}

Adızel, Ö., 1998: Van Gölü Havzası Ornitofaunası Üzerine Araştırmalar. Doktora tezi, Yüzüncüyıl Üniversitesi, Fen Bilimleri Enstitüsü.

Anonim. 1993: Türkiye'nin Sulak Alanları. Türkiye Çevre Vakfı Yayını, Türkiye

Arabac1, M,. Sarı, M. 2004: Induction of ovulation in endemic pearl mullet (Chalcalburnus tarichi), living in the highly alkaline Lake Van, using GnRHa ([d-Ser(tBu)6,Pro9-Net]-GnRH) combined with haloperidol. Aquaculture, 238: 529-535.

Baran İ, Atatür, M. K. 1998: Türkiye Herpetofaunası. Çevre Bakanlığı, Türkiye.

Behçet, L. 1994: Vangölü Makrofıtik Vejetasyonunun Fitososyolojik Yönden Araştırılması, Turkish Journal of Botany, 18:(4), 229-243.

Behçet, L., Altan, Y. 1994: Van, Erçek, Turna ve Bostaniçi Göllerinin Sucul Florası. Doğa Türk Botanik Dergisi, 18: 91-98.

Davis, P., H. 1965-1988: Flora of Turkey and the East Aegean Islands. Edinburgh University Press, Vol. 1-9, Edinburgh.

Davis, P., H. 1988: Flora of Turkey and the East Aegean Islands. Edinburgh University. Press, Vol. 10, Edinburgh.

Dobinson, H. M. 1976: Bird Count. Keztrel Books. Published by Penguin Books Ltd. Hormondsworth.

Güner, A., Özhatay, N., Ekim, T., Başer, K. H. C. (eds) 2000: Flora of Turkey and the East Aegean Islands. Vol.11 (supplement 2): pp. 79-88. Edinburgh: Edinburgh University Press.

Kasparek, M. 1989: Status and Distribution of The Great Bustard and The Little Bustard In Turkey. Bustard Studies, 4: 80-113.
Kence, A. 1987: Türkiye'nin Biyolojik Zenginlikleri. Türkiye Çevre Sorunları Vakfı Yayını, Türkiye.

Kılıç, D. T., Eken, G. 2004. Türkiye'nin Önemli Kuş Alanları-2004 Güncellemesi. Doğa Derneği, Türkiye

Kışlalıŏlu, M., Berkes, F. 1987: Biyolojik Çeşitlilik. Türkiye Çevre Sorunları Vakfı Yayını, Türkiye.

Kumerloeve, H. 1969: Zur Avifauna des Van Gölü und Hakkari Gebietes (E/SE) (Van Gölü-Hakkari Bölgesi (Doğu/Güneydoğu Küçük Asya) Kuşları). İstanbul Üniversitesi Fen Fakültesi Mecmuası, B34: 245-312.

Schilperoord, L., Schilperoord-Huisman, M. 1986: Observations of waterbirds in some wetlands in Turkey. July/August. WIWO-report 14. Zeist, The Netherlends.

Van den Berk, V.M., Cronau, J.P., Van der Have, T.M. 1993: Waterbirds in the Van Province, Eastern Turkey. May 1989. WIWO-report 34, WIWO, Zeist.

Van der Ven, J.A., Gheyselinck, G.F. 1980: Birds in Eastern Turkey II. Unpubl. report.

Vielliard, J. 1968: Türkiye'de Ornitolojik Gezinin Neticeleri (Resultats Ornithologiques d'une mission a travers la Turquie) İstanbul Üniversitesi Fen Fakültesi Mecmuası, Cilt 33, Seri: B: Tabii İlimler, Sayı: 2-467-147.

Yarar, M., Magnin, G. 1997: Türkiye'nin Önemli Kuş Alanları. Doğal Hayatı Koruma Derneği, Türkiye.

Zeyrek,Y., Öztürk, A. 1993: Van Kalesi Florası. Y.Y.Ü., Fen Edebiyat Fakültesi Fen Bilimleri Enstitüsü Dergisi, 2 (2): 4-26. 